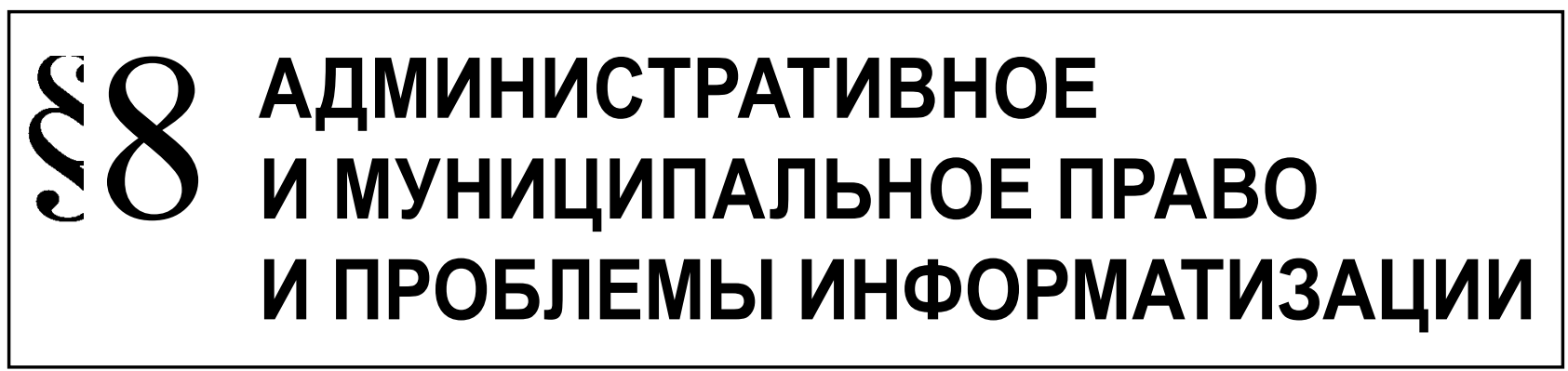

Хуртин Д.О.

\title{
КОМПЕТЕНЦИЯ РОСКОМНАДЗОРА ПО ВЫЯВЛЕНИЮ АДМИНИСТРАТИВНЫХ ПРАВОНАРУШЕНИЙ, ПОСЯГАЮЩИЙ НА ПРАВА ИНТЕЛЛЕКТУАЛЬНОЙ СОБСТВЕННОСТИ В ИНФОРМАЦИОННО-ТЕЛЕКОММУНИКАЦИОННОЙ СЕТИ «ИНТЕРНЕТ»
}

Аннотация: В статье рассматриваются вопросы, связанные с необходимостью выявления административных правонарушений в сети "Интернет", посягающих на права интеллектуальной собственности, по инициативе Федеральной службы по надзору в сфере связи, информационных технологий и массовых коммуникаций, без заявления правообладателя. Общественные отношения находятся на стадии развития, при которой большинство подобных правонарушений совершается в сети "Интернет". Исследуется вопрос: "имеется ли необходимость привлечения к административной ответственности, в случае если правообладатель не сообщал о нарушении его прав?". При написании работы применялся метод анализа, аналогии, моделирования, изучения нормативно-правовых норм и правоприменительной практики. Техническое развитие так или иначе приводит к увлечению числа правонарушений, совершаемых в телекоммуникационной сети "Интернет". Изучение предмета позволяет заключить, что "сегодня" правообладатель не всегда знает о нарушение своих прав, поэтому существует необходимость выявления административных правонарушений, посягающих на права интеллектуальной собственности в сети "Интернет", по инициативе органов государственной власти.

Ключевые слова: административно-правовая защита, права интеллектуальной собственности, выявление административных правонарушений, компетенция Роскомнадзора, массовые коммуникации, административное правонарушение, сеть "интернет", административная ответственность, органы государственной власти, административный надзор.

$\mathrm{C}$ овременное общество на протяжении двадцати лет развивается на основе новых принципов распространения информации. Причиной этому является повсеместное распространение сети «Интернет». В связи с происходящими изменениями перед социумом встает новая проблема - защита авторских прав при размещении объектов в сети. «Нарушения интеллектуальных прав в Интернете представляют собой проблему, для решения которой требуется государственное вмешательство» ${ }^{1}$.

\footnotetext{
1 Кондратьева Е.А. Интеллектуальные права в Интернете:
} соотношение интересов правообладателей и общества // Ин-
Российская Федерация, вслед за мировым сообществом, разрабатывает и принимает комплекс мер, направленных на охрану и защиту прав интеллектуальной собственности в интернетпространстве. Одним из примеров подобного регулирования служит Федеральный закон от 02.07.2013 № 187-Ф3 «0 внесении изменений в отдельные законодательные акты Российской Федерации по вопросам защиты интеллектуальных прав в информационно-телекоммуникацион-

теллектуальная собственность. Авторское право и смежный права. 2014. № 2. С. 45. 
ных сетях»², предусматривающий комплексные изменения в законодательстве. Указанный закон, принятый в июле 2013 года, вносит поправки в Арбитражный процессуальный Кодекс ${ }^{3}$, Гражданский процессуальный Кодекс ${ }^{4}$, Федеральный закон «Об информации, информационных технологиях и о защите информации» ${ }^{5}$. Все они направлены на закрепление механизма блокировки доступа к контенту, нарушающему авторские права, на основании определения Московского городского суда. Следует отметить, что Законодатель на первом этапе ограничился сферой распространения фильмов, в том числе кино- и телефильмов.

Последовательность действий органа исполнительной власти, уполномоченного осуществлять функции по контролю и надзору в сфере информационных технологий и массовых коммуникаций, в полной мере отражена в ст. 15.2 Федерального закона «Об информации, информационных технологиях и о защите информации». Таким органом является Федеральная служба по контролю в сфере связи, информационных технологий и массовых коммуникаций - Роскомнадзор ${ }^{6}$. Вопросы, касающиеся ограничения доступа к ресурсам информационно-телекоммуникационных сетей, в том числе сети «Интернет», и ответственности информационных посредников, не раз становились предметов рассмотрения ученых в области различных отраслей права. Стоит отметить, что в данной ситуации Роскомнадзор играет роль «обеспечивающего механизма», другими словами - является исполнителем решения, вынесенного в порядке гражданского судопроизводства Московским городским судом.

\footnotetext{
2 Федеральный закон от 02.07.2013 № 187-Ф3 «О внесении изменений в отдельные законодательные акты Российской Федерации по вопросам защиты интеллектуальных прав в информационно-телекоммуникационных сетях» // СЗ РФ. 2013. № 27. C. 3479.

3 Арбитражный процессуальный кодекс Российской Федерации от 24.07.2002 № 95-ФЗ (ред. 02.11.2013) // СЗ РФ. 2002. № 30. С. 3012.

4 Гражданский процессуальный кодекс Российской Федерации от 14.11.2002 № 138-ФЗ (ред. от 28.12.2013) // СЗ РФ. 2002. № 46. C. 4532.

5 Федеральный закон от 27.07.2006 № 149-Ф3 (ред. от 28.12.2013) «Об информации, информационных технологиях и о защите информации» // СЗ РФ. 2006. № 31. С. 3448.

6 П. 1 Постановления Правительства РФ от 16.03.2009 № 228 (ред. от 02.11.2013) «О Федеральной службе по надзору в сфере связи, информационных технологий и массовых коммуникаций» // С3 РФ. 2009. 12. С.1431.
}

Обращает на себя внимание тот факт, что Роскомнадзор является органом, уполномоченным выявлять правонарушения, посягающие на права интеллектуальной собственности. Так, согласно Кодекса Российской Федерации об Административных правонарушениях: «ввоз, продажа, сдача в прокат или иное незаконное использование экземпляров произведений или фонограмм в целях извлечения дохода в случаях, если экземпляры произведений или фонограмм являются контрафактными в соответствии с законодательством Российской Федерации об авторском праве и смежных правах либо на экземплярах произведений или фонограмм указана ложная информация об их изготовителях, о местах их производства, а также об обладателях авторских и смежных прав, а равно иное нарушение авторских и смежных прав в целях извлечения дохода, за исключением случаев, предусмотренных частью 2 статьи 14.33 настоящего Кодекса» ${ }^{7}$. Выносить постановления о привлечении к административной ответственности за правонарушения, предусмотренные ст. 7.12 уполномочен лишь один субъект - мировой судья. В то же время, перечень органов, уполномоченных составлять протоколы о подобных административных правонарушениях, весьма широк. К таким органам относятся: органы полиции; таможенные органы; органы, осуществляющие функции по контролю и надзору в сфере защиты прав потребителей и потребительского рынка; органы, уполномоченные в области защиты патентных прав ${ }^{8}$.

Особого внимания заслуживает формулировка п. 58, ч. 2, ст. 28.3 КоАП РФ: «должностные лица органа, осуществляющего функции по контролю и надзору в сфере связи, информационных технологий и массовых коммуникаций, - об административных правонарушениях, предусмотренных...статьей 7.12 (за совершение нарушений в сфере массовых коммуникаций)»9. Закономерно возникает вопрос: что следует понимать под сферой массовых коммуникаций и,

Ч. 1 ст. 7. 12 Кодекса Российской Федерации об административных правонарушениях (ред. от 12.03.2014) // СЗ РФ. 2002. № 1. C. 1 .

8 См.: п.1, п. 12, п. 58, п. 75. ч. 3. ст. 28.3 Кодекса Российской Федерации об административных правонарушениях (ред. от 12.03.2014) // СЗ РФ. 2002. № 1. С. 1.

9 П. 58. ч. 3 ст. 28.3 Кодекса Российской Федерации об административных правонарушениях (ред. от 12.03.2014) // С3 РФ. 2002. № 1. С. 1. 
главное, относится ли сеть «Интернет» к массовым коммуникациям? На сегодняшний день отсутствует легальная дефиниция, которая регулировала бы поставленный вопрос. Согласно Постановления Правительства о Минкомсвязи: «Министерство связи и массовых коммуникаций Российской Федерации (Минкомсвязь России) является федеральным органом исполнительной власти, осуществляющим функции по выработке и реализации государственной политики и нормативно-правовому регулированию в сфере...почтовой связи, массовых коммуникаций и средств массовой информации, в том числе электронных (включая развитие сети Интернет...)» ${ }^{10}$. Обращаясь к энциклопедической литературе, мы отмечаем, что под массовой коммуникацией понимается «один из видов коммуникации (наряду с межличностной и публичной), состоящий в распространении информации в широком пространственно-временном диапазоне в расчете на массовую аудиторию» ${ }^{11}$. Анализируя представленную информацию, можно сделать закономерный вывод - сеть «Интернет» является средством массовой коммуникации. Следовательно, контроль и надзор за соблюдением прав интеллектуальной собственности в интернете, согласно п. 58 ч. 2. ст. 28.3 Кодекса Российской Федерации об административных правонарушениях, относится к компетенции Роскомнадзора.

Представленная аргументация позволяет заключить - Федеральная служба по надзору в сфере связи, информационных технологий и массовых коммуникаций имеет возможность по собственной инициативе выявлять правонарушения, предусмотренные ст. 7. 12 КоАП РФ, и составлять протоколы об административных нарушениях. Следует отметить, что вопросы деятельности должностных лиц Роскомнадзора по составлению протоколов не регламентированы должным образом. Отсутствует административный регламент исполнения данной функции. Действующий «Перечень должностных лиц Федеральной службы по надзору в сфере связи, информационных технологий и массовых коммуникаций и ее территориальных органов, уполномоченных составлять протоколы об администра-

10 П. 1 Постановление Правительства РФ от 02.06 .2008 № 418 (ред. от 02.11.2013) «О Министерстве связи и массовых коммуникаций Российской Федерации» // СЗ РФ. 2008. № 23. C. 2708.

11 Новая философская энциклопедия: в 4 Т. / под ред. В.С. Стёпина. М.: Мысль. 2010. Т. ІІ. С. 282. тивных правонарушениях» ${ }^{12}$ не содержит указаний на составление протоколов об административных правонарушениях по конкретным составам, в отличии от ранее действовавшего ${ }^{13}$. Также, отсутствует практика составления Роскомнадзором протоколов об административных правонарушениях по ст. 7.12 КоАП РФ. Вышесказанное свидетельствует о том, что предоставленные законодателем полномочия не реализуются в полной мере, что, в свою очередь, является неприемлемым. На наш взгляд, это обусловлено несколькими фактами. Во-первых, претензионный порядок защиты прав интеллектуальной собственности. Правообладатель, узнав о незаконном использовании результатов интеллектуальной деятельности, предъявляет требования к нарушителю, обосновывая при этом наличие исключительных прав (иных законных или договорных оснований) у себя и отсутствие законных оснований для использования объектов интеллектуальных прав у нарушителя. Таким образом, орган исполнительной власти, выявивший факт размещения в сети «Интернет» кино- телефильма и не имеющий решения суда об ограничении доступа к ресурсу, на котором расположен данный объект, должен запросить у лица, разместившего объект доказательства, подтверждающее наличие права на такое размещение. И, только в случае, если лицо не представит таких доказательств, может быть составлен протокол об административном правонарушении по ч. 1. Ст. 7.12 КоАП РФ. Во-вторых, важной особенностью субъективной стороны указанного состава, в отличии от аналогичного состава уголовного преступления ${ }^{14}$, является наличие умысла на извлечение дохода. Такое обстоятельство представляется сложным в доказывании, если возмездность пользования, размещенными объектами интеллектуальной собственности прямо не

\footnotetext{
12 Утвержден Приказом Минкомсвязи РФ от 04.05.2010 № 70 (ред. от 16.12.2010) «Об утверждении Перечня должностных лиц Федеральной службы по надзору в сфере связи, информационных технологий и массовых коммуникаций и ее территориальных органов, уполномоченных составлять протоколы об административных правонарушениях» // РГ. 2010. № 5214. С. 44.

13 Приказ Минкомсвязи РФ от 07.04.2009 № 52 «Об утверждении Перечня должностных лиц Федеральной службы по надзору в сфере связи, информационных технологий и массовых коммуникаций и ее территориальных органов, уполномоченных составлять протоколы об административных правонарушениях». // РГ. 2009. № 4908. С. 28.

14 Ст. 146 Уголовного Кодекса Российской Федерации (ред. от 03.02.2014) // СЗ РФ. 1996. № 25. С. 2954.
} 
указана на интернет сайте. В-третьих, стратегия действий правообладателя часто сводится к привлечению к ответственности провайдера: «Проще всего привлечь к судебному спору по такому делу в качестве ответчика провайдера, который уже в суде должен будет доказать отсутствие своей вины в совершенном правонарушении, что чаще всего и происходит» ${ }^{15}$. При этом, на наш взгляд, складывается ситуация, в которой лицо, чаще всего непричастное к нарушению прав интеллектуальной собственности, вынуждено доказывать свою невиновность, неся при этом судебные издержки. Подобная расстановка приоритетов свойственна гражданско-правовым отношениям, поскольку «осуществление гражданских прав основано на свободе выбора управомоченным субъектом в принципе любого варианта поведения, обусловленного содержанием субъективного права» ${ }^{16}$.

Возникает вопрос: стоит ли активизировать функции Роскомнадзора по самостоятельной деятельности в сфере выявления нарушений интеллектуальных прав в сети «Интернет»? Как отмечают ведущие ученые в области административного надзора: «Государственная экономическая политика России направлена, прежде всего, на создание благоприятного климата для усиления предпринимательской активности в стране и устранение административных барьеров, на первый план выходит построение эффективного механизма реализации контролирующей функции государства» ${ }^{17}$. Учитывая общественные настроения, можно предположить, что осуществление полномочий по самостоятельному выявлению правонарушений будет излишним, однако, нельзя не согласится с мнением Каткова П.В., о том, что усиление контроля в данной сфере «угрожает лишь одному - бизнесу недобросовестных предпринимателей, зарабатывающих на пиратской (воровской) модели в сети интернет» ${ }^{18}$. Сложившаяся административно-правовая модель защиты авторских прав перестает функционировать

15 Васильева Т.В. О соблюдении авторских прав в эпоху развития высоких технологий // Современное право. 2011. № 5. C. 103.

16 Аникин А.С. Содержание и осуществление субъективного гражданского права // Юрист. 2008. № 3. С.62.

17 Никифоров М.В., Мартынов А.В. Современное исследование вопросов правового регулирования государственного контроля // Журнал российского права. 2013. № 6. С. 148.

18 П. Катков. Угроза для недобросовестных предпринимателей // ЭЖ-юрист. 2013. № 5. С. 5. с необходимой эффективность. До последнего времени большинство протоколов об административных правонарушениях, предусмотренных ст. 7.12 КоАП РФ составлялось должностными лицами органов полиции и федеральной службы по контролю и надзору в сфере защиты прав потребителей и благополучия человека в ходе проверок торговых объектов. Правонарушение представляло собой продажу материальных носителей, содержащих объекты прав интеллектуальной собственности, так называемые «пиратские» CDDVD диски. Развитие техники привело к массовому распространению указанных правонарушений в интернете. Таким образом, возникла ситуация, при которой органы государственной власти должны по собственной инициативе выявлять подобные правонарушения в сети «Интернет».

На сегодняшний день является возможной самостоятельная деятельность Роскомнадзора по выявлению нарушений прав интеллектуальной собственности в сети «Интернет» в отношении фильмов, кино- телефильмов. Данная категория объектов подлежит государственной регистрации: «Регистрации подлежат все кино- и видеофильмы российского, зарубежного и совместного производства, используемые в целях: тиражирования и распространения; сдачи в прокат и аренду; публичной коммерческой и некоммерческой демонстрации; трансляции по кабельному телевидению на территории Российской Федерации» ${ }^{19}$. Наличие сведений о фильмах в государственном регистре ${ }^{20}$ позволяет органам Роскомнадзора, в случае наличия оснований для составления протокола об административном правонарушении, предусмотренном ст. 7.12 КоАП РФ, узнать зарегистрирован ли определенный фильм в регистре, и кто является обладателем исключительных прав на его распространение. Поскольку «при передаче прав владения, пользования и (или) распоряжения кино- и видеофильмом владелец прокатного удостоверения передает юридическому или физическому лицу нотариально удостоверенную копию прокатного удостоверения, о чем письменно уведомляет Министерство культуры Российской Федерации не

\footnotetext{
19 П. 1 Постановления Правительства РФ от 28.04.1993 № 39 (ред. от 26.01.2007) «О регистрации кино- и видеофильмов и регулировании их публичной демонстрации» // САПиП РФ. 1993. № 18. С. 1607.

20 Поиск фильмов в государственном регистре [Официальный сайт Министерства культуры Российской Федерации] // URL: http://mkrf.ru/registr/ (дата обращения: 16.03.2014 г.).
} 
позднее трех дней со дня совершения сделки» ${ }^{21}, \mathrm{y}$ контролирующих органов в распоряжении имеется актуальная информация о всех сделках совершенных в отношении каждого кино- телефильма. Таким образом, органы Роскомнадзора, при выявление факта распространения в целях извлечения дохода экземпляров кино- телефильмов, смогут оперативно получить информацию о наличии или отсутствии у распространителя законных оснований для такого распространения и на основе полученных данных принять решение о составлении протокола об административном правонарушении или об отсутствии события административного правонарушений.
На наш взгляд, введение подобной практики является необходимым условием для административно-правовой защиты прав интеллектуальной собственности в интернете. Принятие регламента, устанавливающего процедуру осуществления контроля и надзора за соблюдением прав интеллектуальной собственности в сфере массовых коммуникаций, позволит в полной мере задействовать предоставленные п. 58, ч. 2, ст. 28.3 Кодекса Российской Федерации об административных правонарушениях полномочия Федеральной службе по контролю и надзору в сфере связи, информационных технологий и массовых коммуникаций полномочия.

\section{Библиография:}

1. Арбитражный процессуальный кодекс Российской Федерации от 24.07.2002 № 95-Ф3 (ред. 02.11.2013) // СЗ РФ. 2002. № 30.

2. Гражданский процессуальный кодекс Российской Федерации от 14.11.2002 № 138-Ф3 (ред. от 28.12.2013) // СЗ РФ. 2002. № 46.

3. Журнал российского права. 2013. № 6.

4. Интеллектуальная собственность. Авторское право и смежный права. 2014. № 2.

5. Кодекс Российской Федерации об административных правонарушениях (ред. от 12.03.2014) // С3 РФ. 2002. № 1.

6. Новая философская энциклопедия: в 4 Т. / под ред. В.С. Стёпина.

7. Постановление Правительства РФ от 28.04.1993 № 39 (ред. от 26.01.2007) «0 регистрации кино-и видеофильмов и регулировании их публичной демонстрации» // САПиП РФ. 1993. № 18.

8. Постановление Правительства РФ от 02.06.2008 № 418 (ред. от 02.11.2013) «0 Министерстве связи и массовых коммуникаций Российской Федерации» // СЗ РФ. 2008. № 23.

9. Постановление Правительства РФ от 16.03.2009 № 228 (ред. от 02.11.2013) «О Федеральной службе по надзору в сфере связи, информационных технологий и массовых коммуникаций» // СЗ РФ. 2009. 12.

10. Приказ Минкомсвязи РФ от 07.04.2009 № 52 «Об утверждении Перечня должностных лиц Федеральной службы по надзору в сфере связи, информационных технологий и массовых коммуникаций и ее территориальных органов, уполномоченных составлять протоколы об административных правонарушениях». // РГ. 2009 . № 4908.

11. Приказ Минкомсвязи РФ от 04.05.2010 № 70 (ред. от 16.12.2010) «Об утверждении Перечня должностных лиц Федеральной службы по надзору в сфере связи, информационных технологий и массовых коммуникаций и ее территориальных органов, уполномоченных составлять протоколы об административных правонарушениях» // РГ. 2010. № 5214.

12. Современное право. 2011. № 5.

13. Уголовный Кодекс Российской Федерации (ред. от 03.02.2014) // СЗ РФ. 1996. № 25.

14. Федеральный закон от 27.07.2006 № 149-ФЗ (ред. от 28.12.2013) «Об информации, информационных технологиях и о защите информации» // СЗ РФ. 2006. № 31.

15. Федеральный закон от 02.07.2013 № 187-Ф3 «О внесении изменений в отдельные законодательные акты Российской Федерации по вопросам защиты интеллектуальных прав в информационно-телекоммуникационных сетях» // СЗ РФ. 2013. № 27.

16. ЭЖ-юрист. 2013. № 5.

17. Юрист. 2008. № 3.

18. Юрист. 2008. № 7.

\section{References (transliterated):}

1. Arbitrazhnyi protsessual'nyi kodeks Rossiiskoi Federatsii ot 24.07.2002 № 95-FZ (red. 02.11.2013) // SZ RF.2002. № 30.

21 П. 5 Постановления Правительства РФ от 28.04.1993 № 39 (ред. от 26.01.2007) «О регистрации кино- и видеофильмов и регулировании их публичной демонстрации» // САПиП РФ. 1993. № 18. С. 1607. 


\section{Административное и муниципальное право $9(81) \cdot 2014$}

2. Grazhdanskii protsessual'nyi kodeks Rossiiskoi Federatsii ot 14.11.2002 № 138-FZ (red. ot 28.12.2013) // SZ RF. 2002. № 46.

3. Zhurnal rossiiskogo prava. 2013. № 6.

4. Intellektual'naya sobstvennost'. Avtorskoe pravo i smezhnyi prava. 2014. № 2.

5. Kodeks Rossiiskoi Federatsii ob administrativnykh pravonarusheniyakh (red. ot 12.03.2014) // SZ RF. 2002 . № 1.

6. Novaya filosofskaya entsiklopediya: v 4 T. / pod red. V.S. Stepina.

7. Postanovlenie Pravitel'stva RF ot 28.04.1993 № 39 (red. ot 26.01.2007) «0 registratsii kino-i videofil'mov i regulirovanii ikh publichnoi demonstratsii» // SAPiP RF. 1993. № 18.

8. Postanovlenie Pravitel'stva RF ot 02.06.2008 № 418 (red. ot 02.11.2013) «0 Ministerstve svyazi i massovykh kommunikatsii Rossiiskoi Federatsii» // SZ RF. 2008. № 23.

9. Postanovlenie Pravitel'stva RF ot 16.03.2009 № 228 (red. ot 02.11.2013) «O Federal'noi sluzhbe po nadzoru v sfere svyazi, informatsionnykh tekhnologii i massovykh kommunikatsii» // SZ RF. 2009. 12.

10. Prikaz Minkomsvyazi RF ot 07.04.2009 № 52 «Ob utverzhdenii Perechnya dolzhnostnykh lits Federal'noi sluzhby po nadzoru v sfere svyazi, informatsionnykh tekhnologii i massovykh kommunikatsii i ee territorial'nykh organov, upolnomochennykh sostavlyat' protokoly ob administrativnykh pravonarusheniyakh». // RG. 2009. № 4908.

11. Prikaz Minkomsvyazi RF ot 04.05.2010 № 70 (red. ot 16.12.2010) «Ob utverzhdenii Perechnya dolzhnostnykh lits Federal'noi sluzhby po nadzoru v sfere svyazi, informatsionnykh tekhnologii i massovykh kommunikatsii i ee territorial'nykh organov, upolnomochennykh sostavlyat' protokoly ob administrativnykh pravonarusheniyakh» // RG. 2010. № 5214.

12. Sovremennoe pravo. 2011. № 5 .

13. Ugolovnyi Kodeks Rossiiskoi Federatsii (red. ot 03.02.2014) // SZ RF. 1996. № 25.

14. Federal'nyi zakon ot 27.07.2006 № 149-FZ (red. ot 28.12.2013) «Ob informatsii, informatsionnykh tekhnologiyakh i o zashchite informatsii» // SZ RF. 2006. № 31.

15. Federal'nyi zakon ot 02.07 .2013 № $187-\mathrm{FZ} « 0$ vnesenii izmenenii v otdel'nye zakonodatel'nye akty Rossiiskoi Federatsii po voprosam zashchity intellektual'nykh prav v informatsionno-telekommunikatsionnykh setyakh» // SZ RF. 2013 . № 27.

16. EZh-yurist. 2013. № 5 .

17. Yurist. 2008. № 3.

18. Yurist. 2008. № 7. 